\title{
Problem-Based Learning as an Effective Tool for Teaching Computer Network Design
}

\author{
Nigel Linge and David Parsons
}

\begin{abstract}
This paper addresses the challenge of developing techniques for the effective teaching of computer network design. It reports on the experience of using the technique of problem-based learning as a key pedagogical method for teaching practical network design within the context of a Master's program module in data telecommunications and networks at the University of Salford, Salford, Greater Manchester, U.K. A two-threaded approach was adopted that comprised a problem-based learning thread and a conventional lecture thread. The problem-based learning thread within the module comprised sessions designed to place the students in the position of network design consultants who are introduced to scenarios that have a high degree of realism in which a client has specific business requirements that can be met through the adoption of a network solution. In this way, the problem-based learning thread allows the students to develop their design skills, while the lecture thread uses traditional teaching methods to allow students to develop their understanding of key network components and architectures. A formal evaluation of this approach has been carried out and demonstrated a very effective and realistic learning experience for the students. Therefore, the authors propose that problem-based learning is an ideal pedagogical tool for the teaching of computer network design.
\end{abstract}

Index Terms-Computer network design, M.Sc. degree, problem-based learning.

\section{INTRODUCTION}

$\mathbf{T}$ HE M.Sc. degree in data telecommunications and networks was launched by the University of Salford, Salford, Greater Manchester, U.K., in October 1990 to provide students with specialized knowledge of the operation and fundamentals of computer networking. Within two years of its launch, recruitment grew to 20 students annually, and it has never fallen below that figure, recording a record intake high of 43 full-time students during the 1999-2000 academic year. The period since the introduction of the M.Sc. degree has also witnessed a dramatic change in the adoption and use of computer networking technology. Once seen only as applicable to telecommunication companies and specialist organizations, such as universities, a computer network is now an essential business tool. Indeed, such is the reliance on modern computer networking technology and infrastructures that most organizations have a dependency culture where their business and market performance are often directly linked to the performance of their network. Even in the home market, the last 14 years has seen a dramatic increase in personal computer ownership, Internet usage, and

Manuscript received October 4, 2004; revised April 12, 2005.

The authors are with the School of Computing, Science and Engineering, University of Salford, Salford, Greater Manchester M5 4WT, U.K. (e-mail: n.linge@salford.ac.uk).

Digital Object Identifier 10.1109/TE.2005.852600 now connection to broadband access networks. The uptake of mobile technology has been even more significant, with well over $80 \%$ of the U.K. population owning a mobile telephone. The net result of all of these changes is that, in today's world, the demand for individuals with a knowledge of computer networking and, particularly, the ability to design a network to meet the needs of an organization, has grown to cover all commercial and public sectors.

The M.Sc. degree in data telecommunications and networks has similarly evolved to meet this changing need in the marketplace. Whereas in the early days students required highly specialized technical knowledge of networking components and systems, the demand now is for the ability to apply network technology to real life situations. There has been a shift from deep technical knowledge to application and usage. Modules on digital signal processing and filter theory, for example, have in recent years been replaced by modules covering wireless network systems and network architectures. Students who once only considered seeking jobs with companies that specialized in equipment manufacture or the provision of telecommunication services now see job opportunities in companies within the retail, public, and service sectors. From an educational point of view, this growth has brought with it a requirement to change the focus from the development of technical knowledge and understanding to one of network system design. The "teaching" of design has, therefore, become a key challenge for the program team and forms the main subject of this paper.

\section{NETWORK ARCHITECTURES AND DESIGN}

The latest major syllabus review of the M.Sc. degree in data telecommunications and networks introduced a new module called "network architectures and design" for the 2003-2004 cohort of students. This 15-credit, second semester, level M (Master's) module is intended to provide the students with an appreciation and understanding of how well different network designs perform and, most important, the design process through which a network can be created to meet a given user requirement. This module builds upon a first-semester module on computer networking that has provided a comprehensive underpinning of networking technologies and communication protocols. In semester 2, the key requirement is to build upon the first module and move forward to develop a strong theoretical knowledge of how network components can be integrated to produce complete systems and how the performance of these systems can be analyzed to determine how effectively the network design satisfies user requirements. The process of design involves the analysis of user requirements and their 


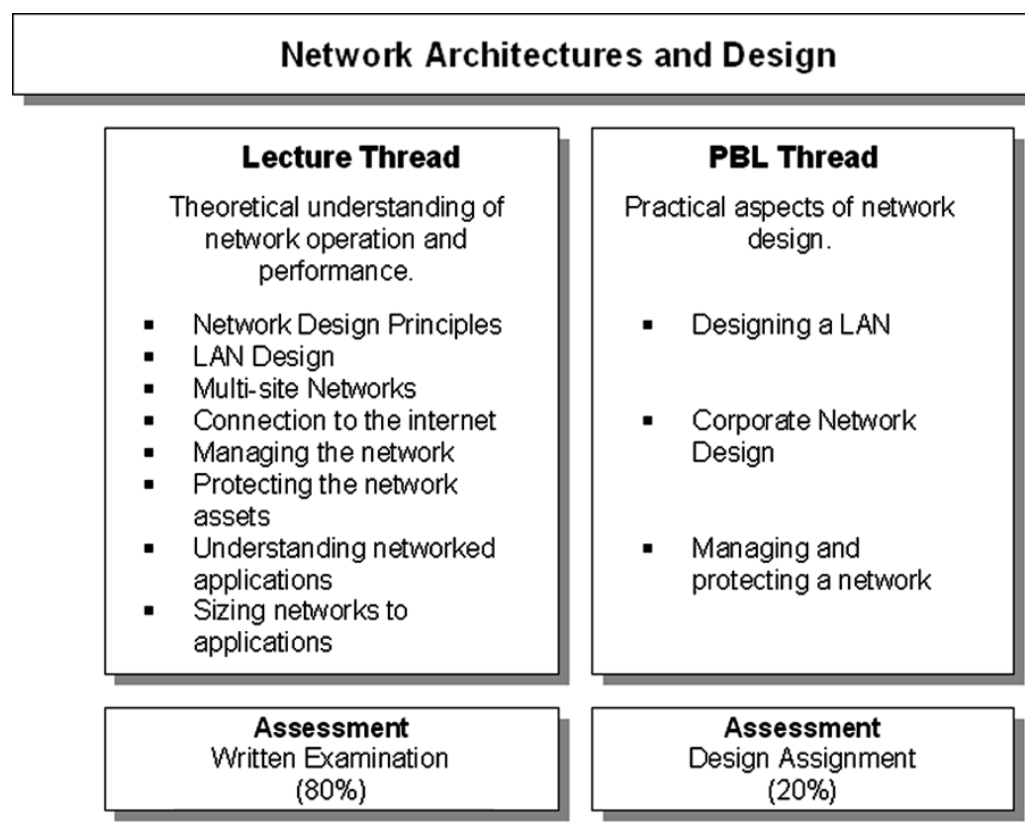

Fig. 1. Two-threaded approach.

translation into a technical solution that is ultimately a compromise resulting from balancing technology against budget [1].

The authors of this paper acted as facilitators for this new module, being responsible for its design and delivery. Linge has a broad experience and knowledge of computer networking resulting from his research and teaching work. Parsons is a Visiting Professor who has an extensive industrial experience in the design and operation of U.K. and global scale networks. The challenge was how to transfer this extensive experience effectively to provide students with a worthwhile and beneficial learning experience.

\section{The StRATEGiC AdOPTION OF PROBLEM-BASED LEARNING}

Design, by its very nature, is problem driven; therefore, from the outset, problem-based learning (PBL) has been identified as the pedagogical tool best suited to the teaching of the network architectures and design module [2].

Gendron and Jarmoszko [3] have successfully exploited PBL to teach data communications and networking to undergraduate students studying information systems. Here, a two-thread framework is employed in which a theoretical thread provides the fundamental theory, and an applied thread uses a business-case simulation tool to experience practical business issues. Equally, Noor [4] has applied PBL to the teaching of a third-year undergraduate module on network design and management. A traditional PBL approach was adopted for the whole module where an initial tutorial session presented small groups of students with a scenario that drove the learning of subsequent sessions. At Oxford Brookes University, Oxford, U.K. [5], PBL has been applied to the teaching and learning of a network construction and administration module at the M.Sc. level, while at Edge Hill College, Ormskirk, Liverpool, U.K. [6], a PBL approach has been exploited to teach an undergraduate computer networking module.
When developing the pedagogical model for delivering the M.Sc. module in network architectures and design, a decision was made to adopt a two-threaded approach [7] similar to that used by Gendron and Jarmoszko. This model has proven to be successful and, therefore, forms a good basis for the introduction of PBL for the first time into the M.Sc. degree in data telecommunications and networks. Since only one module within the M.Sc. program was adopting PBL, importance was placed on ensuring that the student experience would not, in any way, be disadvantaged through employing a PBL methodology. Hence, a decision was also taken to introduce PBL strategically over a two-year period. In year 1 (2003-2004), PBL would be used alongside traditional lectures to address purely the network design aspects of the module, extending in year 2 (2004-2005) to adopting a full PBL approach for the delivery of the whole module. Transition to the year 2, full PBL version would also be dependent upon the success of and reflection upon the year 1 PBL experience.

\section{A Two-THREADED APPROACH}

The key aims of the new module were to ensure that students gained a general theoretical understanding of the design, operation, and performance of network architectures and to appreciate the practical issues and processes involved in actual network design. To achieve these goals, a two-threaded delivery approach was adopted as shown in Fig. 1. This approach comprised a lecture thread that was used to convey the theoretical understanding of network operation and performance and a PBL thread that was intended to develop the student's practical network design skills

The lecture thread was delivered as 20 hours of lectures and four hours of tutorials in which the class contact sessions were used for discussion and debate of key issues, being supplemented with detailed printed materials given to students and supported with online material made available through the 
university's virtual learning environment. This aspect of the module was carefully designed to take the students on a journey through network design. It started with the basic principles of network design. These were then applied to the design of a simple, small-scale local area network (LAN). From here, the concept of multisite networks, followed by how private networks can be interfaced to the Internet, was considered. Next, a review and understanding of network management followed, which led into a detailed analysis of issues relating to protecting an organization's network assets. Finally, the thread concluded with an in-depth review of the operation of networked applications and how networks need to be designed properly to deliver such applications efficiently. Assessment of the lecture thread was carried out by a formal written examination, which carried a weighting of $80 \%$.

The PBL thread comprised nine hours of class contact and was designed to complement the lecture thread by placing the students in a situation where they were required to work with real-life network design problems. Here, PBL was used specifically to develop network design skills and not as a vehicle by which the students themselves would drive their learning of networks. In year 2, however, the intention is that PBL will indeed be used to drive a student's learning to acquire both technical design skills and theoretical understanding of network systems.

\section{Design of The PBL Thread}

Network design begins with a user requirement-the problem. However, this problem is often ill-defined so that the role of the network designer is to work closely with his or her client to develop a complete specification from which a practical design can be developed, honed, and, ultimately, implemented. A major concern in the development of the PBL thread, therefore, was to ensure that the design scenarios and PBL triggers were as realistic as possible. Here, the practical design experience of the authors was used to maximum effect.

To this end, students were organized into small teams of four or five and asked to take on the role of network design consultants. A United Kingdom-based client, "P\&L Interior Designs," was conceived and said to have approached the network design consultants to provide the client with a network solution for their business. A deliberate decision was taken to ensure that P\&L Interior Designs was a company that used information and communications technology (ICT) but was not an ICT company. This decision was especially significant, for students on a specialized Master's program in computer networking often tend to be technology focused and orientated, whereas, in reality, most clients are not.

Hence, P\&L Interior Designs was defined in the following way.

P\&L Interior Designs is a small-to-medium enterprise (SME) that specializes in providing interior design services to commercial organizations. The enterprise offers expertise in space planning and customizing physical environments to meet an organization's needs. Using its state-ofthe-art computer design facilities and a range of third-party suppliers, P\&L Interior Designs is uniquely placed to deliver custom-designed furniture, fixtures, and fittings, and hence providing a full service from drawing board to fully fitted interiors.

Equally important was ensuring that the PBL triggers were all business, rather than technology, driven. Again, this emphasis reflects the majority of real-life scenarios where most organizations do not have a strong understanding of, or necessarily a desire to understand, the intricate details of network technology or design. Today, networks, while technically complex in their design and operation, are often simply "tools" used to ensure that a business can function and deliver its services effectively. Students working toward the M.Sc. degree in data telecommunications and networks, on the other hand, are highly technology focused and driven; therefore, an important aspect of their learning is for them to realize that the vast majority of customers or clients that they are likely to meet do not share these same passions. Being able to translate technological knowledge into business language that a client can understand is an essential skill that students need to acquire.

A total of three PBL sessions were arranged within the module, with each having its own trigger, but also with each session building on the previous one, in effect, remaining in synchronism with the lecture thread, as shown in Fig. 2. The first trigger presented the students with a scenario in which their client (P\&L Interior Designs) had recently acquired new business premises in Manchester, U.K., and required a LAN design for this building. A brief history of P\&L Interior Designs was given in which it was explained that the company had its headquarters based in Cheltenham, U.K., and had already established one regional office in Greenwich, U.K. PBL session 1 came at a point within the module at which basic LAN operation had been covered. However, the PBL session purely described the operation of the client's business and what functions it intended to carry out at its new premises. In addition, a detailed description of the new business premises was made available. Hence, the key point of this first PBL session was to encourage the students to use their technical knowledge, acquired from the lecture thread, and apply it to producing an outline design that would form the basis of a first meeting between the network design consultants (the students) and the client. This outline design comprised a basic network architecture but did not identify a precise component list. As a result, students learned how to determine a client's networking needs from a knowledge of their business operation and processes, to decide which technologies are best suited to meet these requirements and to understand how physical restrictions, such as those imposed by a building, can also influence network design.

PBL session 2 had as its trigger a desire on the part of P\&L Interior Designs to determine how it could rationalize its business processes by centralizing certain of its key business activities in Cheltenham. This centralization was to be achieved by establishing a corporate network that interconnects all of its three sites and provides communications so that the physical location of staff is not a hindrance to the operation of the business. As an example of how this requirement was expressed in business, rather than technical terms, the following is an extract of the brief given to the students. 


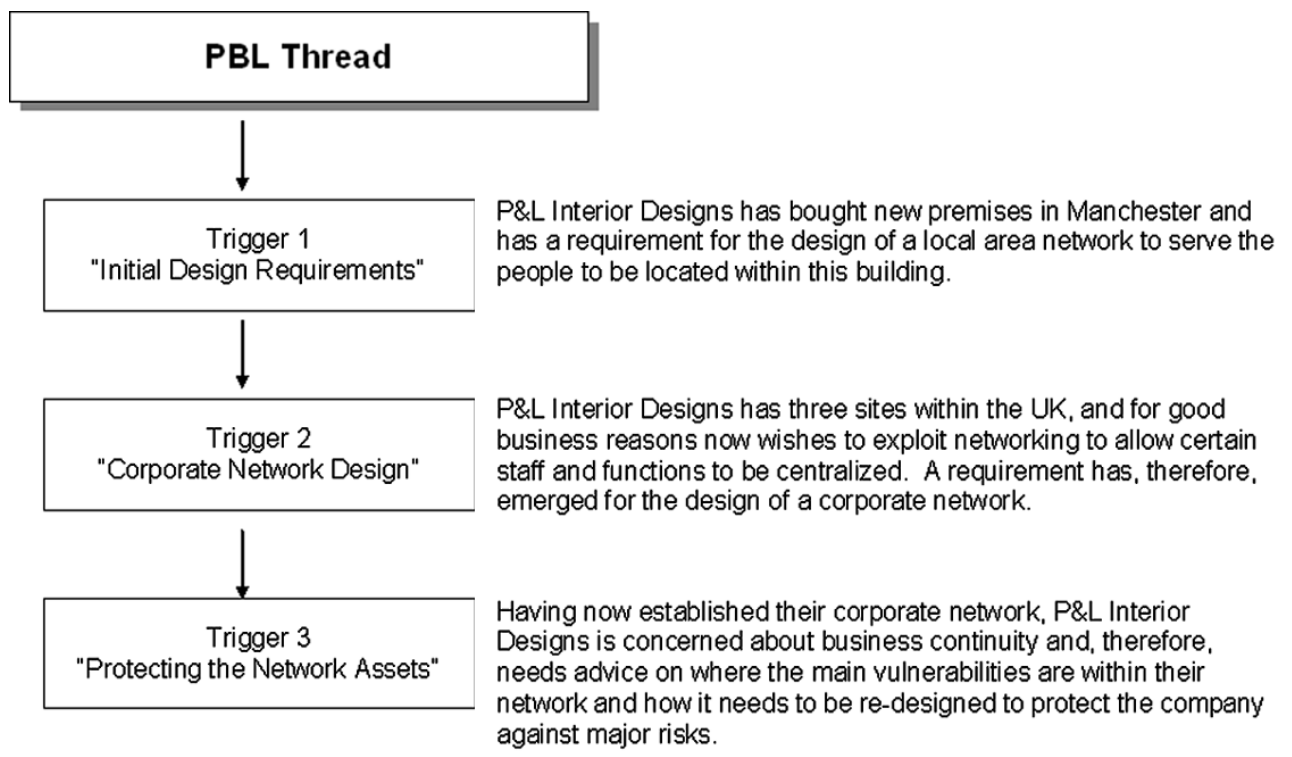

Fig. 2. PBL thread.

In order to improve the overall efficiency of the company and to facilitate core business growth, the company wants to relocate all of the administration and financial services to the headquarters site and to free space and staff within the Greenwich and Manchester regional offices to expand the design and customer-support functions. The corporate network will enable centralization of customer records, all financial functions (invoice processing, financial transactions tracking and payment), personnel data for the company, and a design archive storage. In addition, the network is seen as being able to support a new companywide e-mail service and to allow Internet access from any of the three company locations. There is a desire for members of the customer planning and surveying team to access company resources from customer sites and home.

While not an immediate requirement, P\&L Interior Designs is also interested in the potential for linking their network to the networks of third-party suppliers for the purposes of direct electronic ordering and secure financial transactions.

Again, this session was scheduled to occur at a time when the basic concepts of corporate networks had been covered by the lecture thread. The key focus of this second PBL session was, therefore, to develop the student's skills in the design of networks that are used to interconnect sites over large distances. Here, an essential element was for the students to understand what business benefit the client was trying to obtain from a corporate network and to determine the networking and communications needs that existed both within the three sites themselves and among the three sites. Knowledge of these dynamics determine which network technologies and designs will be most suitable. A key learning objective was to convince the students that the latest, fastest technology is not always the best option but choosing technological solutions that fit the purpose is essential. At the conclusion of the PBL session, students were able to identify a range of appropriate network technologies that could be used to interconnect the client's sites to form the basis of their corporate network. As with the first session, however, students were not required to produce a final detailed design.

The third and final PBL session focused on the scenario that P\&L Interior Designs had established its corporate network, linking its sites in Cheltenham, Greenwich, and Manchester, providing external connection to the Internet. Now, the company has become concerned about business risks and business continuity. The students, acting as network design consultants, have been approached again to undertake a critical evaluation of the client's network, to identify the prime areas of risk and the likely business impacts of these risks, and to suggest any required modifications to the network to manage the risks identified. The main learning outcome was for the students to understand how network design has a direct impact on the operation of a business. The lecture thread had by this time considered how to analyze networks and identify areas of weakness and single points of failure. This PBL session, however, presented the students with a business, not a network, context from which they had to identify the key risks to the client. At the end of this session, students were able to produce a prioritized list of the main areas of the client's network that presented the most risk to their business processes and continuity.

Throughout the PBL thread, students were presented with triggers and information that were written in terms of business and organization operation, rather than technology. This policy was deliberately chosen to reflect reality and to force students to realize that real network design is always client, not technology, driven. Although the three PBL sessions were not in themselves explicitly assessed, the design experience gained by the students was assessed by means of a module assignment that carried a weight of $20 \%$. This assignment comprised a network specification from which the students were required to produce a complete and detailed network design using commercially available components.

Throughout the PBL thread, the main objective was to develop the students' ability to undertake network design based on identified business requirements, not to develop their knowl- 
TABLE I

PBL SESSION QUESTIONNAIRE RESULTS

\begin{tabular}{l|l}
\hline Question & Satisfaction Level \\
\hline $\begin{array}{l}\text { The PBL sessions have improved my understanding of } \\
\text { the lectures provided within this module. }\end{array}$ & $88 \%$ \\
\hline $\begin{array}{l}\text { The PBL sessions have helped my understanding of } \\
\text { the theoretical network design process. }\end{array}$ & $80 \%$ \\
\hline $\begin{array}{l}\text { The PBL sessions have improved my understanding of } \\
\text { the practical aspects of network design. }\end{array}$ & $70 \%$ \\
\hline $\begin{array}{l}\text { Having participated in the PBL sessions, my } \\
\text { confidence and ability to undertake a real network } \\
\text { design has been enhanced. }\end{array}$ & $70 \%$ \\
\hline $\begin{array}{l}\text { The PBL sessions were realistic and reflected typical } \\
\text { real practical situations. }\end{array}$ & $66 \%$ \\
\hline $\begin{array}{l}\text { The PBL sessions have helped my ability to work in } \\
\text { groups. }\end{array}$ & $77 \%$ \\
\hline The PBL sessions were well organized and effective. & $78 \%$ \\
\hline $\begin{array}{l}\text { The PBL sessions should be kept as part of this } \\
\text { module. }\end{array}$ & $86 \%$ \\
\hline
\end{tabular}

edge of network technology per se. Overall the combination of the PBL and lecture threads enabled the complete set of module objectives to be realized and fully met.

\section{ORGANIZATION OF THE PBL SESSIONS}

For each of the three PBL triggers, a three-hour timetable session was allocated on a staggered basis within the 12-week semester. All 27 students were divided into self-organized groups of four or five, and these groups remained together for all PBL sessions. At the start of each session, a brief was given for the PBL trigger, which comprised a set of printed materials and a short introduction by the module facilitators. Students were then given the task of working on the brief, within their respective groups, for approximately two hours. During this time, the module facilitators acted as the "client" and were able to provide additional information. A key aspect to the design of the PBL briefs was that a degree of incompleteness was built-in. Again, this plan reflects reality in which all relevant information is rarely provided at the start, and a process of consultation and questioning must be entered into to arrive at a fully developed specification from which a technical design can be produced. Such an approach allowed the students to recognize that they both needed and were allowed to ask further questions of the client. They had to learn how to communicate technical queries in language that could be understood by a nonexpert client. The module facilitators had tried to preempt a list of likely questions that would be asked to ensure that a standard and consistent answer could be given. Where groups appeared to be struggling or going off at a tangent, the module facilitators did intervene to guide them back onto the right track. This aspect of the sessions worked very well with a high degree of interaction within the groups and good discussion with the module facilitators.

The final hour of each session was assigned for groups to present their design and findings to the whole class. With each presentation, the module facilitators provided a technical critique and invited other groups to comment and compare their approach to that which had been presented. Discussion and debate were good at this point.

Overall, the PBL sessions were manageable within the time, although, with only three hours available, the level of detail accomplished by each design was limited. However, since the intention was to educate students in the process of design, this limitation was not felt to be a particular problem. Many groups did continue working on the PBL briefs after the conclusion of the session, exhibiting a very positive outcome. Presenting the students with the brief at the start of each session is potentially an inefficient approach since groups do require time to familiarize themselves with the material. For future years, the intention is to make the PBL briefs available via the university's virtual learning environment one week in advance.

\section{EVALUATION}

Since the launch of the M.Sc. degree in data telecommunications and networks in the 1990-1991 academic year, network design has always been included within the syllabus. However, as the M.Sc. degree and the networking field developed, so network design has taken on an increasingly important significance and prominence. The culmination of this development has been the introduction of the new module in network architectures and design for the 2003-2004 academic year. Within the context of this new module has come the phased introduction of PBL to facilitate student learning. A key requirement was to ascertain the students' perceptions of the new module, specifically the use and effectiveness of PBL as a pedagogical methodology. To achieve this assessment, an evaluative questionnaire was developed and given to the students at the end of the final PBL session. The results from this questionnaire are presented in Table I in which students were asked to score each question in the range of 0 to 4 and where the satisfaction level is a weighted average of these scores for each question. A maximum score given by all students for a given question would result in a satisfaction level of $100 \%$ for that question. 
TABLE II

PBL SESSION QUESTIONNAIRE-GENERAL QUESTIONS

\begin{tabular}{l} 
General Questions \\
\hline 1. What aspects of the PBL sessions did you enjoy the most? \\
\hline 2. What aspects of the PBL sessions did you dislike the most? \\
\hline 3. Tell us how the PBL sessions could be improved.
\end{tabular}

Overall strong support for the specific use of PBL is exhibited in this questionnaire. This support is evidenced by the consistently high satisfaction levels, with all respondents strongly rating PBL as having helped their understanding of the theoretical network design process. Similarly, students acknowledge that the PBL sessions have improved their understanding of the practical aspects of network design. Students have also generally acknowledged that the PBL sessions have helped to enhance their confidence in being able to undertake network design in the future. The PBL sessions have assisted the students, the authors believe, in being able to work in groups. Finally, support exists for PBL to be retained as a key pedagogical tool for the delivery of this module.

The evaluative questionnaire also provided students with an opportunity to provide additional comments about the three general questions listed in Table II. A very strong response to question 1 was the group work aspect of PBL and being able to hear the presentation made by each of the other groups. For question 2, three main themes emerged: the desire for larger/smaller groups, the need for more time scheduled for the PBL sessions, and the desire for constructive feedback to be given by the module facilitators on the quality of each group's presentation and their design decisions. Interest was also expressed by the students in being able to analyze each other's designs and provide a technical critique. Finally, for question 3, a strong desire was expressed for the PBL sessions to be more practically bedded in terms of real network products and scenarios and for the module facilitators to provide their own "worked solutions" for comparison purposes. Overall, however, strong support existed for the use of PBL, and a clear expression by the students that PBL had assisted their learning.

The final mark for the module was obtained from an $80 \%$ contribution from a formal written examination and a $20 \%$ contribution from an individual network design assignment. From a total of 27 students who studied this module, the average for the network design assignment was $63 \%$ with a standard deviation of 11.9 against a general pass mark of 50\% for Master's level study.

\section{CONCLUSION}

This paper has described the experience and philosophy behind the introduction of PBL to facilitate the teaching of network design to students working toward the M.Sc. degree in data telecommunications and networks at the University of Salford, Salford, Greater Manchester, U.K. Teaching students how to undertake practical "design" represents a challenge. A twothreaded approach was adopted in which a lecture thread was used to develop the students' general understanding of network technology and its operation and performance, and a PBL thread that was used to develop design skills. The design of the PBL thread exploited the practical experience of the module facilitators and allowed the students to take on the role of network design consultants, working on a total of three scenarios that had a strong practical dimension and realism. Evaluation of this PBL thread has indicated generally strong support from the student cohort, reflected in an encouraging set of results obtained from the network design assignment.

Based on the experience of introducing PBL to this new M.Sc. module and the feedback obtained from the students, the intention is to move to phase 2 of the strategic adoption of PBL. For the 2004-2005 academic year, the wholesale adoption of PBL was used as the tool by which the module was delivered and all of its learning outcomes achieved.

\section{REFERENCES}

[1] M. Norris and S. Pretty, Designing the Total Area Network. New York: Wiley, 2000.

[2] M. Savin-Baden and C. Howell Major, Foundations of Problem-Based Learning. Maidenhead, U.K.: Open Univ. Press, 2004.

[3] M. Gendron and A. T. Jarmoszko, "Teaching data communications and networking to school of business undergraduates: A pedagogical framework for juxtaposing theory and practice," Proc. Informing Science IT Education (InSITE) Conf., pp. 1145-1153, Jun. 2003.

[4] Rafidah Md. Noor, "Implementing a problem based learning for undergraduate course: A first experience," presented at the The Learning Conf. 2003: What Learning Means, Jul. 15-18, 2003, Institute of Education, Univ. of London.

[5] Network construction and administration-A problem based learning approach (2005, Jan. 17). [Online]. Available: http://www.ics.ltsn.ac.uk/pub/pbl/OxfordBrookes.doc.

[6] Applying PBL in computing-Potential and challenges. Case1: Computer networking (2005, Jan. 17). [Online]. Available: http://www.ics.ltsn.ac.uk/pub/pbl/PBLCase1.doc.

[7] N. Linge and D. Parsons, "Exploiting problem based learning for the teaching of computer network design," presented at the Problem-Based Learning 2004, A Quality Experience? A Three Day Int. Conf., Salford, Greater Manchester, U.K., Sep. 15-19, 2004.

Nigel Linge is currently Head of the School of Computing, Science and Engineering at the University of Salford, Greater Manchester, U.K., where he led the team that developed and launched the M.Sc. degree in data telecommunications and networks in October 1990. He was Program Leader for this M.Sc. program for eight years and has continually delivered at least one module for the full history of the program. He also leads the Centre for Networking and Telecommunications Research and has a broad portfolio of computer-network-related research work involving industry and the public sector and for which U.K. Research Council funding was obtained.

David Parsons was previously responsible for the design and implementation of the Barclays Bank U.K. and global network. At the time of his retirement from Barclays, he was Advanced Technology Director. Since retirement, he has utilized his extensive industrial experience in the banking industry by providing technical consulting services to a range of clients and has enjoyed a close and long association with several U.K. universities, including the University of Salford, Greater Manchester, U.K., where he is currently a Visiting Professor. 